METALLURGY AND FOUNDRY ENGINEERING - Vol. 35, 2009, No. 1

\author{
Rafał Stadnik*, Jan Kazanecki**
}

\title{
INVESTIGATION OF HYDROFORMING OF THE Y-SHAPE BRANCH
}

\section{INTRODUCTION}

Hydroforming is a cost-effective way of shaping workable metals such as aluminum or brass into lightweight, structurally stiff and strong pieces. One of the largest applications of hydroforming is the automotive industry, which makes use of the complex shapes possible by hydroforming to produce stronger, lighter, and more rigid unibody structures for vehicles. This technique is particularly popular with the high-end sports car industry and is also frequently employed in the shaping of aluminium tubes for bicycle frames $[1,2]$.

Hydroforming is a relatively new process, popularised by design studies which suggest that automobiles can be made much lighter by using hydroformed components made of steel. Structural strength and stiffness can be improved and the tooling costs reduced because several components can be consolidated into one hydroformed part. Components manufactured by forming can springback, meaning that the undergo elastic distortion on removing the component from the die. This effect is apparently smaller in hydroformed components.

One advantage is that large components with complex shapes can be made in one step, although the productivity tends to be small because the forming is slow and there is time involved in mounting and unmounting the blank from the hydroforming press. The parts currently produced using THF (Tube Hydroforming) are illustrated in Figure 1 [3-5].

Hydroforming is a specialized type of die forming that uses a high pressure hydraulic fluid (water with oil as a lubricant agent) to press room temperature working material into a die. To hydroform aluminum or steel into a vehicle's frame rail, a hollow tube is placed inside a dies that have the shape of the desired end result. High pressure hydraulic pistons

* Ph.D.: DELPHI Poland S.A., ul. Podgórki Tynieckie 2, 30-399 Kraków; Rafal.Stadnik@delphi.com

** Prof., Ph.D., D.Sc.: Faculty of Metals Engineering and Industrial Computer Science, AGH - University of Science and Technology, Kraków, Poland; kazaneck@metal.agh.edu.pl 
then inject a fluid at very high pressure inside the tube which causes it to expand until it matches the dies cavity. The hydroformed tube is then removed from the dies.

Hydroforming allows complex shapes with concavities to be formed, which would be difficult or impossible with standard solid die stamping. Hydroformed parts can often be made with a higher stiffness to weight ratio and at a lower per unit cost than traditional stamped or stamped and welded parts.

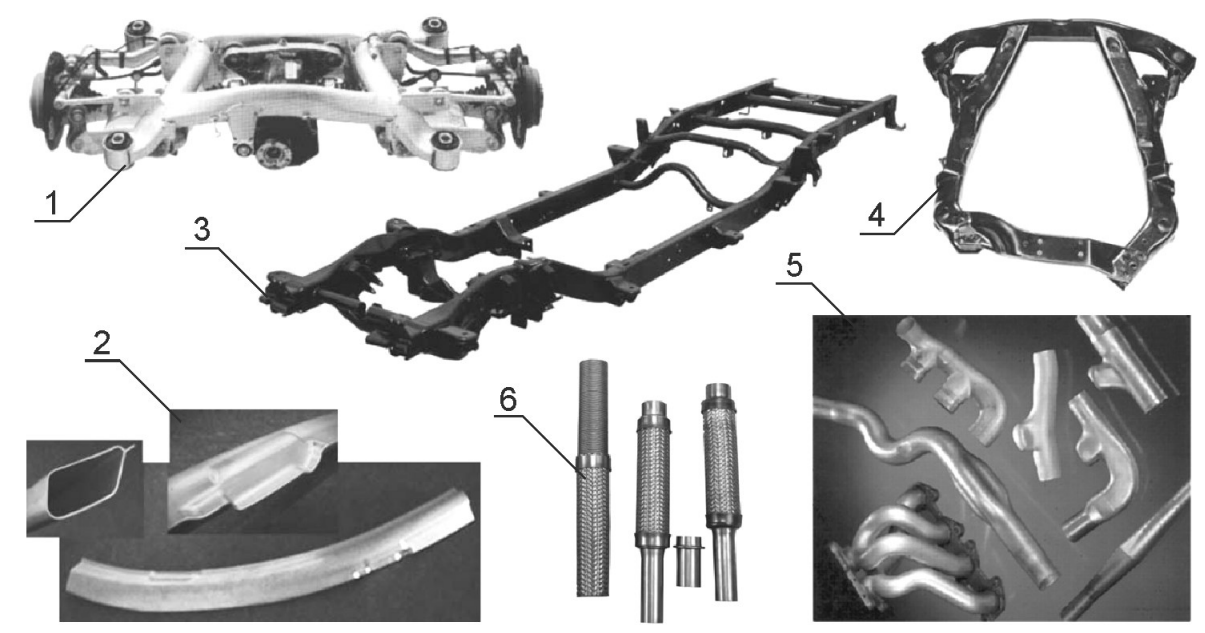

Fig. 1. Applications of hydroforming: 1) rear axle, 2) body frame part, 3) frame, 4) engine subframe, 5-6) exhaust system components

The process design of hydroformed Y-shapes (3-way connectors with an angled branch) was discussed in this paper. These components are the most common parts hydroformed for exhaust system applications. The simple equations were used in order to estimate all of the necessary process parameters (e.g. internal pressure, axial feeds and initial tube length). These estimated parameters where then inserted to the FE simulations. As an initial shape for the simulations the tubular blank made from low carbon steel was used.

\section{MECHANICS OF THE Y-SHAPE HYDROFORMING PROCESS}

In this hydroforming operation a straight tube blank was placed, coated with a liquid film lubricant (oil), in the die cavity that corresponds to the final shape of the component and seals the ends by the axial punches. Then the tube blank is formed internally by using high-pressure oil, while subjecting it to axial compressive stresses from the action of the axial punches. These loads expand the tube wall to the die cavity, Figure 2 [3].

A typical Y-shape hydroforming operation involves a controlled application of internal pressure and axial feed of tube material from the tube ends. Appropriate loading path (axial feed vs. internal pressure) is the right way to achieve the defect-free final Y-shape and with required dimensions. During computer simulation as well as experiment utilizing 
of loading path curve was the main problem. The initial path of the axial feeding vs. internal pressure was determined during experiment and then was implemented to the FEM simulation where was improved. Such final path was introduced to the experiment to achieve the final shape without failures. Example of the loading path was illustrated in Figure 3 [6-8].

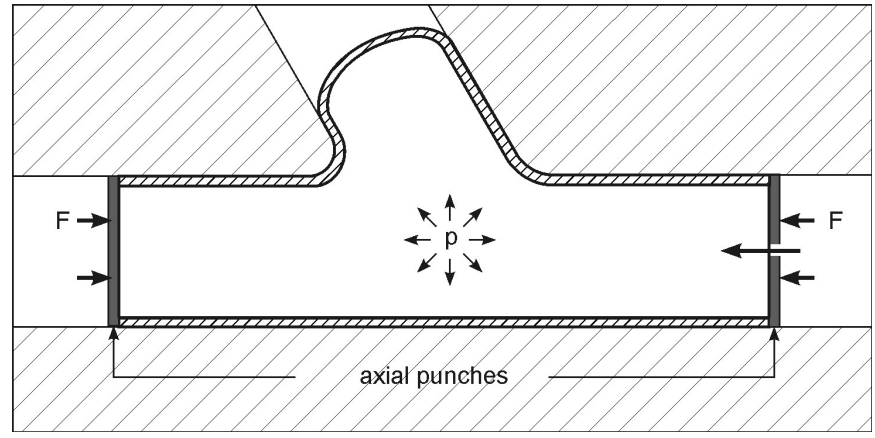

Fig. 2. Hydroforming process of the Y-shape

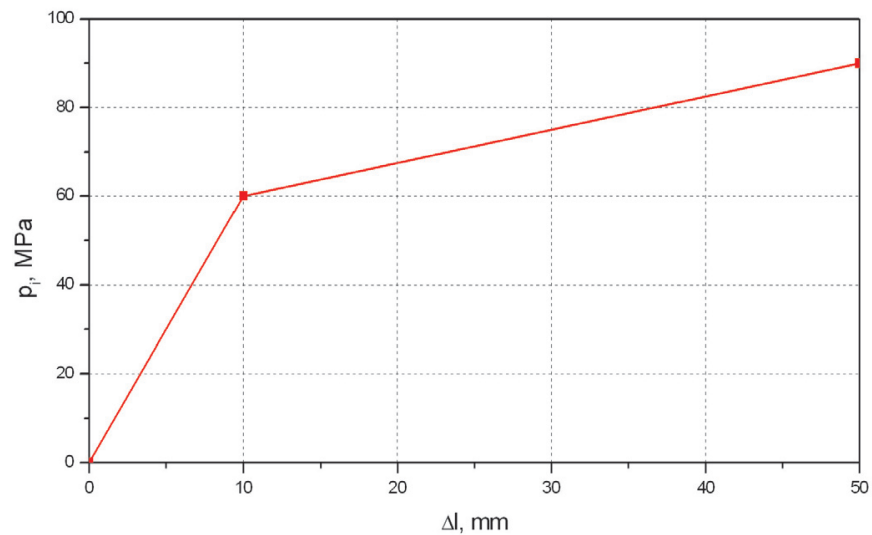

Fig. 3. Example of the loading path

\section{DIMENSIONS OF THE CONSIDERED Y-SHAPES}

In this paper three Y-shapes with different geometrical parameters as well as steel grade were investigated. In all cases, the Y-shapes have the same angle $\alpha=60^{\prime}$, and branch radius equal die radius $r_{b}=r_{o}=16,1 \mathrm{~mm}$, as shown in Figure 4. For the simulations as well as experiment two different initial lengths of tubular blanks were investigated, $l_{0}=140 \mathrm{~mm}$ and $l_{0}=130 \mathrm{~mm}$ for X2CrTi12, E235 and E235+N steel grades respectively. For each tubular blank exact pressure curves were prepared, as it was described in Table 1. Values described in brackets characterized the maximum pressure that was reached at the end of hydroforming process. The left and right axial strokes $\Delta s / 2$ have the same distances and equal $25 \mathrm{~mm}$. 


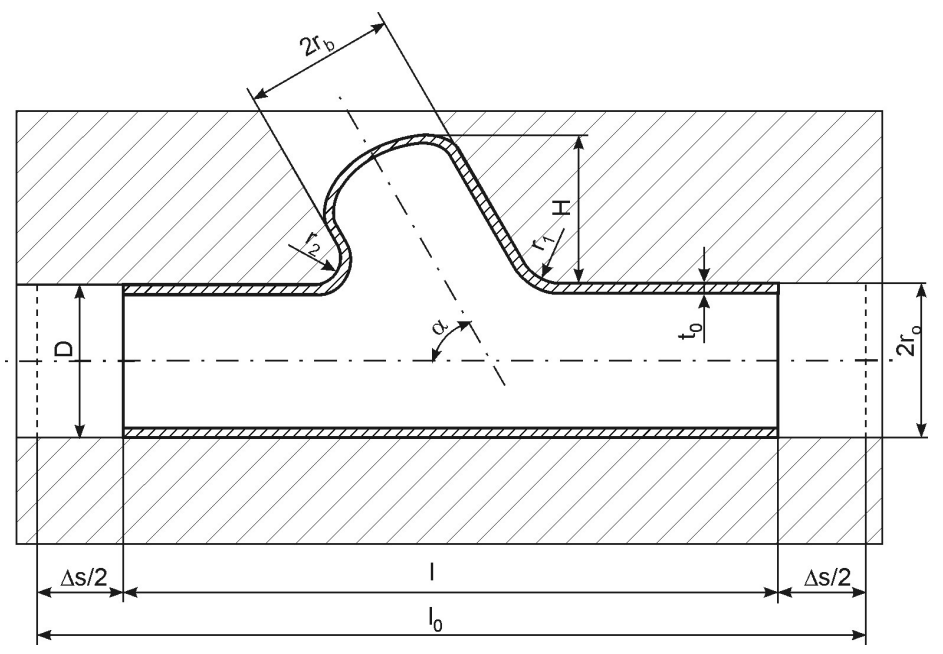

Fig. 4. Geometrical parameters of the Y-shape

Table 1. Geometrical parameters of the Y-shapes

\begin{tabular}{|c|c|c|c|c|c|c|}
\hline $\begin{array}{l}\text { Initial } \\
\text { length }\end{array}$ & $\begin{array}{l}\text { Outsider } \\
\text { diameter of } \\
\text { the tubular }\end{array}$ & $\begin{array}{c}\text { Wall } \\
\text { thickness }\end{array}$ & Steel grade & \multicolumn{2}{|c|}{$\begin{array}{c}\text { Material } \\
\text { parameters }\end{array}$} & \multirow{2}{*}{$\begin{array}{c}\begin{array}{c}\text { Pressure curves } \\
\text { during } \\
\text { simulations }\end{array} \\
\mathrm{p}, \mathrm{MPa}\end{array}$} \\
\hline $1_{0}, \mathrm{~mm}$ & $\mathrm{D}, \mathrm{mm}$ & $\mathrm{t}_{0}, \mathrm{~mm}$ & & $\mathrm{n}$ & $\mathrm{K}, \mathrm{MPa}$ & \\
\hline 140 & 32 & 1,2 & $\begin{array}{c}\text { X2CrTi12 } \\
\text { alloyed } \\
\text { stainless steel }\end{array}$ & 0,228 & 765 & $\begin{array}{c}\mathrm{p}_{1}(63,5) \\
\mathrm{p}_{2}(61) \\
\mathrm{p}_{3}(56,5)\end{array}$ \\
\hline 140 & 32 & 1,5 & $\begin{array}{c}\text { E235 } \\
\text { unalloyed steel }\end{array}$ & 0,234 & 702 & $\begin{array}{l}\mathrm{p}_{4}(77) \\
\mathrm{p}_{5}(74) \\
\mathrm{p}_{6}(55)\end{array}$ \\
\hline 130 & 32 & 1,2 & $\begin{array}{c}\mathrm{E} 235+\mathrm{N} \\
\text { unalloyed steel } \\
\text { after } \\
\text { normalisation }\end{array}$ & 0,242 & 705 & $\begin{array}{c}\mathrm{p}_{7}(50,5) \\
\mathrm{p}_{8}(45) \\
\mathrm{p}_{9}(36)\end{array}$ \\
\hline
\end{tabular}

Loading parameters - During hydroforming process the tubular blank is open to the defects, eg. local thinning and bursting or wrinkling, Figure 5. In order to avoid such instability and within required dimensional tolerance the appropriate rules are given. It is mean that internal pressure versus displacement curves need to be calculated and designed properly in coordination with axial feeding $[6,9,10]$. In order to prepare right internal pressure sequence the yielding as well as bursting pressure could be estimate by the simple equations. 


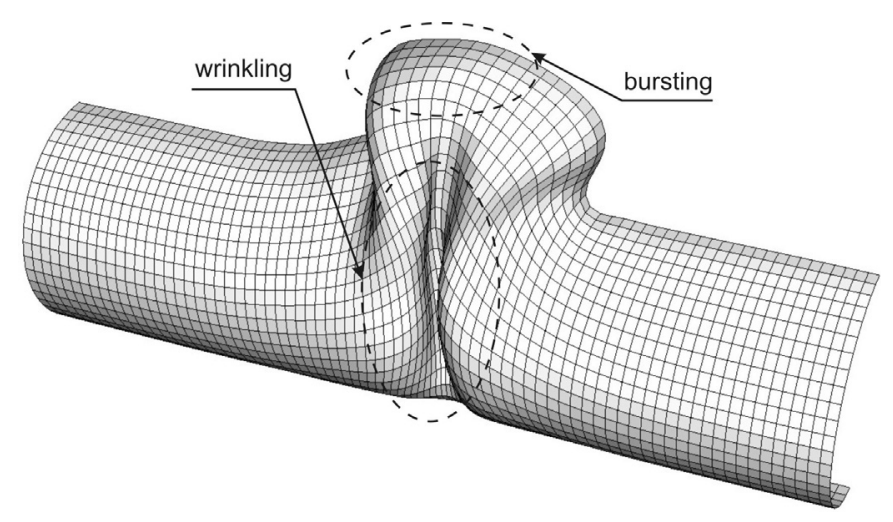

Fig. 5. Defects of the tube wall

Yielding pressure $\left(P_{i}\right)_{y}$ is the minimum pressure required to start tube deformation in the hydroforming process. The analytical model to approximate the yielding pressure is based on a simple axisymmetric bulging of a tube with fixed ends and gives a good initial guess:

$$
\left(P_{i}\right)_{y}=\frac{2 \sigma_{y} t_{0}}{D-t_{0}}
$$

Bursting pressure $\left(P_{i}\right)_{b}$ is the maximum pressure that can form the tube without bursting and can be estimated as follows:

$$
\left(P_{i}\right)_{b}=\frac{4 \sigma_{u} t_{0}}{2 r_{b}-t_{0}}
$$

where:

$\sigma_{u}$ and $\sigma_{y}-$ ultimate tensile and yield strength of the material respectively; strength of the material;

$t_{0}-$ tube initial thickness;

$2 r_{b}$ - branch diameter;

$D_{0}$ - outside diameter of the tubular blank.

After determining these two pressure limits, the designer can construct a first initial pressure curve for hydroforming of the corresponding Y shape by using linear lines connecting these pressure limits. Using iterative FEM simulations, the optimal pressure curves were determined. In the present study, however, the optimal pressure curve was determined through the experimental trial and then was implemented in to the FE simulations.

\section{NUMERICAL INVESTIGATION OF THE HF PROCESS}

FEM simulations as well as geometrical shapes of the Y-shape hydroforming process were conducted using commercial ABAQUS/CAE software [11]. Computer simulations 
estimated and refined the process parameters (internal pressure, axial feeds) and these parameters were used to form the $\mathrm{Y}$ shapes in the experiments. Geometrical model that was used during simulation consists of: two dies, two axial punches and tube (Fig. 6).

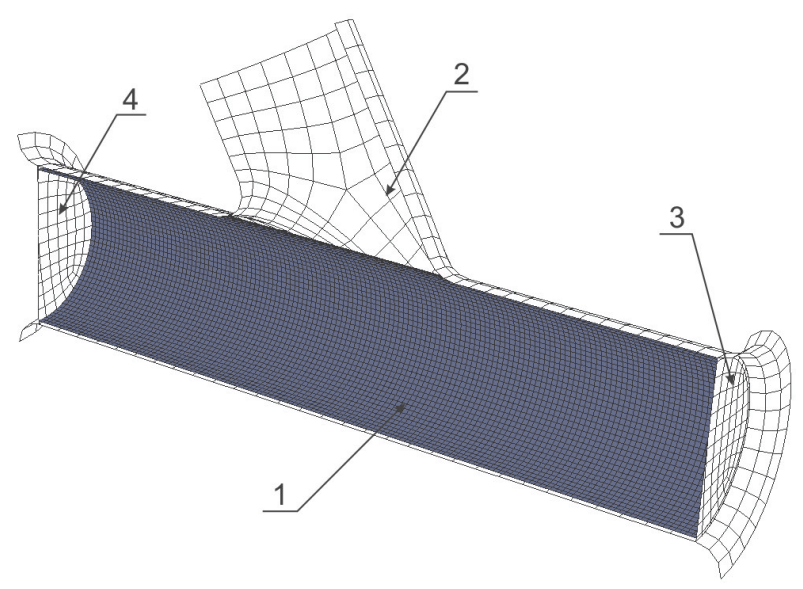

Fig. 6. Geometrical model of the Y-shape: 1 -tubular blank; 2-die; 3, 4-axial punches

During the ABAQUS/CAE simulation the tube was meshed using shell elements, dies and punches were modeled as the rigid surfaces. The deformation behavior of the tube material was isotropic. The friction coefficient is uniform at all points and equals 0.1. The friction coefficient was described through experimental tests for similar friction pairs [8]. Table 2 presents the initial material and tube parameters used for present analysis. These parameters were determined through the axial tension experimental tests [8]. These materials are widely used in automotive industry especially for exhaust components, therefore choosing such kind of steel was well-grounded.

Table 2. Material parameters used in the FEM of the Y-shape

\begin{tabular}{|c|c|c|c|c|c|c|c|c|c|c|c|c|c|c|c|}
\hline \multirow{2}{*}{$\begin{array}{l}\text { Steel } \\
\text { grade }\end{array}$} & \multicolumn{11}{|c|}{ Chemical analysis, $\%$} & \multicolumn{4}{|c|}{ Mechanical properties } \\
\hline & $\mathrm{C}$ & $\mathrm{Mn}$ & $\mathrm{Si}$ & $\mathrm{P}$ & $S$ & $\mathrm{Cr}$ & $\mathrm{Ni}$ & $\mathrm{Cu}$ & $\mathrm{Al}$ & $\mathrm{N}_{2}$ & $\mathrm{Ti}$ & $\begin{array}{c}\sigma_{\mathrm{y}} \\
\mathrm{N} / \mathrm{mm}^{2}\end{array}$ & $\begin{array}{c}\sigma_{\mathrm{u}}, \\
\mathrm{N} / \mathrm{mm}^{2}\end{array}$ & $\begin{array}{c}\mathrm{A}_{50} \\
\%\end{array}$ & $\mathrm{R}$ \\
\hline $\begin{array}{c}\text { X2CrTi1 } \\
2\end{array}$ & 0,06 & 0,75 & 1 & 0,04 & 0,02 & 11,6 & 0,5 & - & - & 0,02 & 0,3 & 240 & 450 & 32 & - \\
\hline E235 & 0,12 & 0,44 & 0,09 & 0,011 & 0,009 & 0,02 & 0,01 & 0,02 & - & - & - & 278 & 407 & 30,0 & - \\
\hline $\mathrm{E} 235+\mathrm{N}$ & 0,11 & 0,47 & 0,18 & 0,013 & 0,007 & 0,02 & 0,02 & 0,13 & - & - & - & 267 & 431 & 43,3 & - \\
\hline
\end{tabular}

\section{FEM RESULTS}

At the beginning of the Y-shape hydroforming study as a two crucial parameters the internal pressure $p$ and axial stroke $s$ were determined. Numerical simulation was performed for different pressure paths illustrated on Figure 7 [8]. 
a)

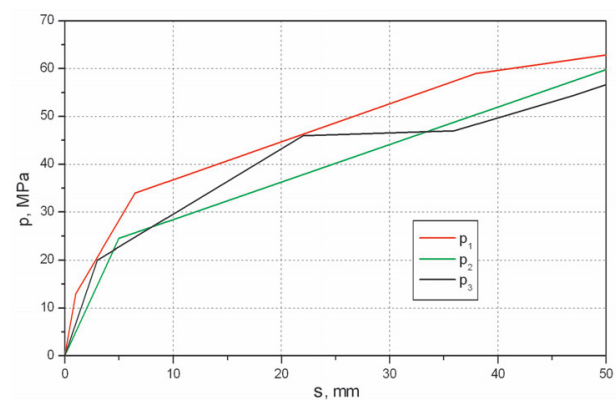

b)

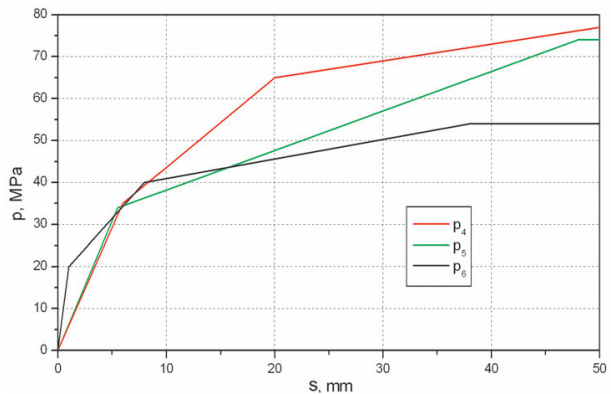

c)

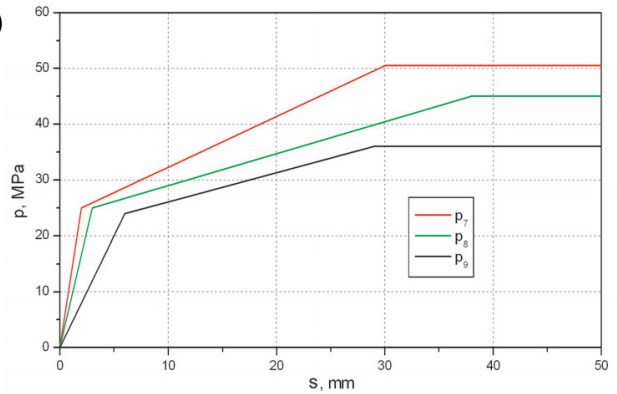

Fig. 7. Pressure paths vs. axial punches stroke for steel grades: a) $p_{1-3}-X 2 C r T i 12$; b) $p_{4-6}-E 235$; c) $p_{7-9}-E 235+N$

For the pressures described above the optimum paths were $p_{2}, p_{5}$ and $p_{8}$. It means that for these pressures the shapes of the Y-shapes were the best. In the next part of this paper only $p_{2}, p_{5}$ and $p_{8}$ pressures were taking into consideration, because Y-shapes hydroformed by this pressure were the optimal shape. Increasing the forming pressure causes thinning at the top of the branch. As expected, higher internal pressure restricts the material flow into the expansion zone. It is caused by increased friction force between tube and dies.

Figure 8 shows a comparison of thickness variations of the Y-shape predicted with FEM for various pressure paths. As expected, maximum thickening at the end of the Y-shape was for the largest value of the pressure path [12]. The simulation results predicted a sound Y-shape with the maximum thinning at the top of the branch, that were $16.4 \%, 20.1 \%$ and $13 \%$ for $p_{2}, p_{5}$ and $p_{8}$ respectively.

Figure 9 shows equivalent plastic strain distributions for $p_{2}, p_{5}$, and $p_{8}$ pressures at the end of the process. For different pressure paths the largest differences in the values of the equivalent strain for each pressure at the top of the branch are observed. In this area maximum value of the strain was for $p_{1}$ pressure, whereas minimum value was for $p_{3}$.

Additionally, figure 10 shows the different axial forces obtained from hydroforming of the Y-shapes with $p_{2}, p_{5}$, and $p_{8}$ pressures. It can be seen that the maximum value of the force $\left(F_{5}\right)$ corresponds to the maximum wall thickness. In case of the same wall thickness the maximum value of each force $\left(F_{2}\right.$ bigger then $\left.F_{8}\right)$ corresponds to the maximum value of each pressure. 
a)

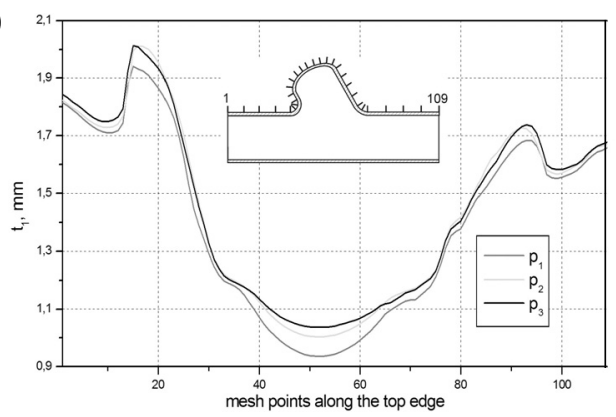

b)

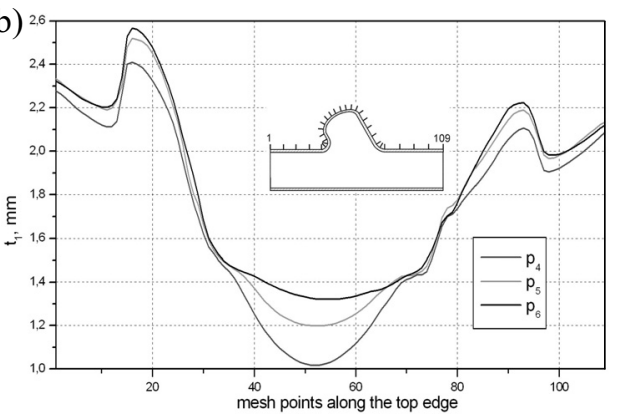

c)

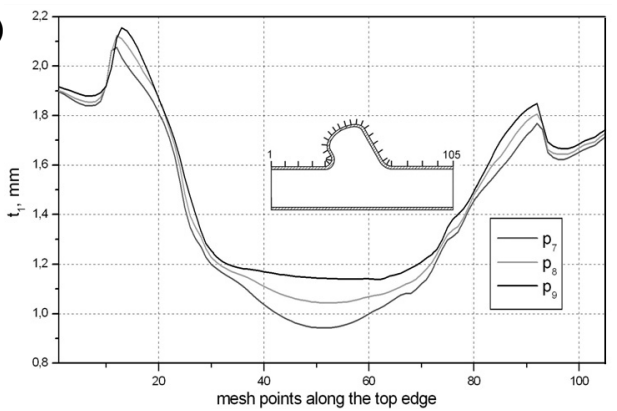

Fig. 8. Wall thickness variations for different pressure paths along the top edge of the final part for steel grades: a) $p_{1-3}-X 2 C r T i 12$; b) $p_{4-6}-E 235$; c) $p_{7-9}-E 235+N$
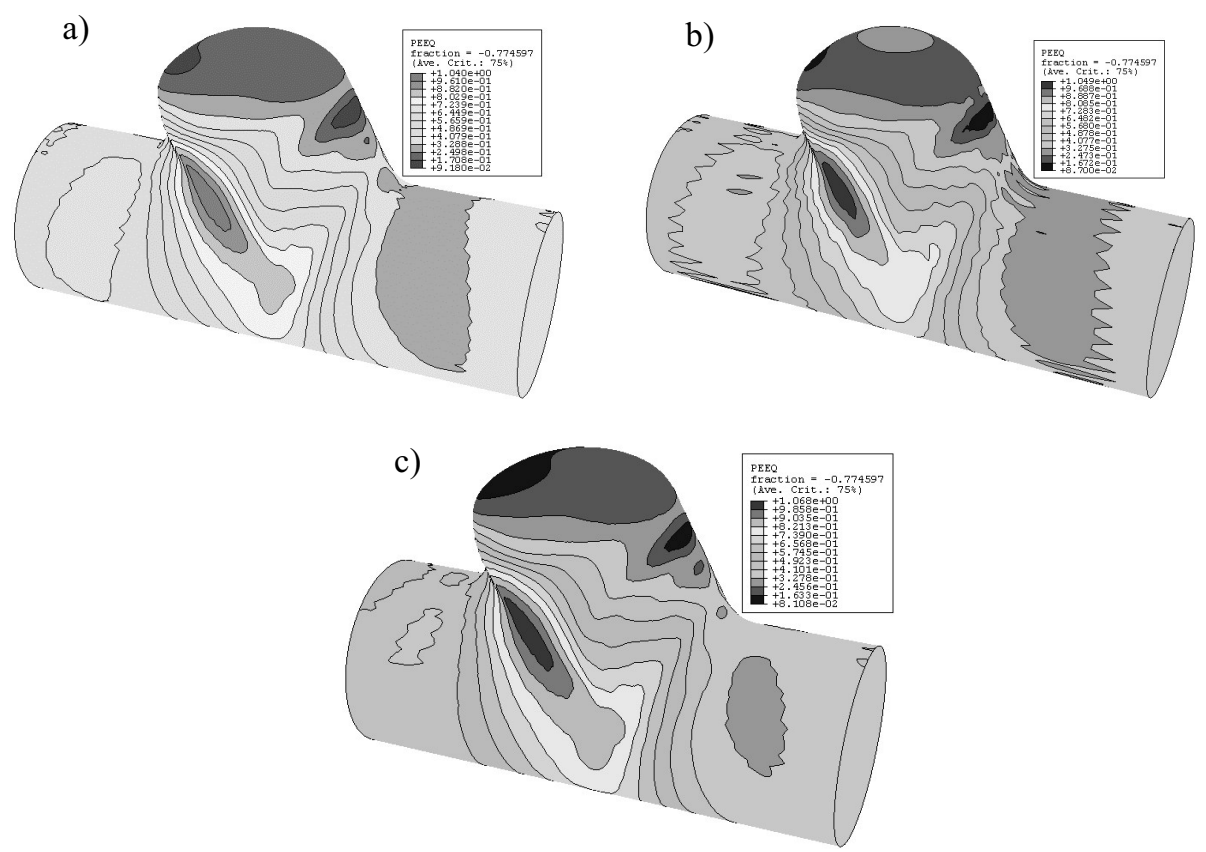

Fig. 9. Equivalent plastic strain distributions for different pressure paths: a) $p_{2}$; b) $p_{5}$; c) $p_{8}$ 
a)

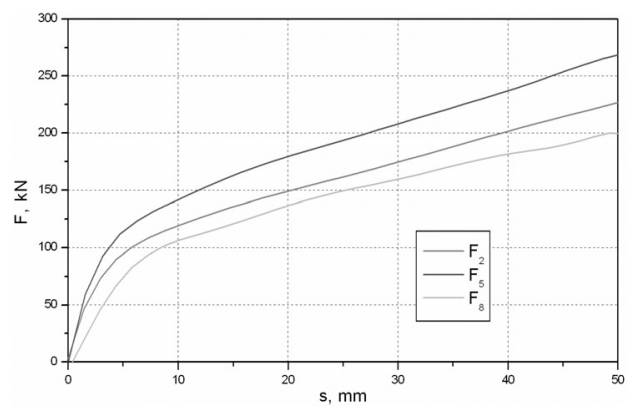

b)

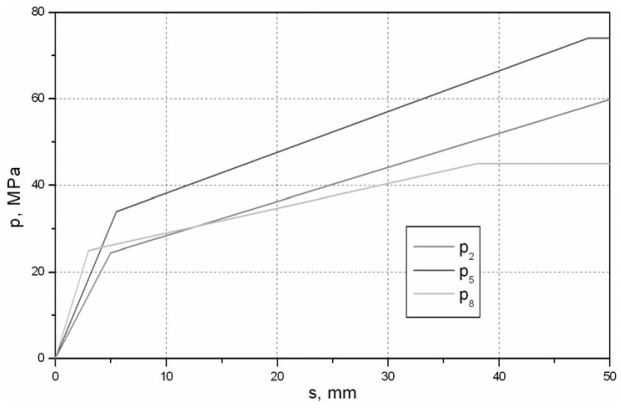

Fig. 10. Axial forces variations (a) for pressures $p_{2}, p_{5}$, and $p_{8}(b)$

\section{EXPERIMENTAL INVESTIGATION}

The experimental investigations were performed to obtain optimal process parameters and to verify the numerical simulations. They allow produce final parts without any faults. The experiment was performed on the hydroforming stand (ZD 100 press, Fig. 11a) that was consisted of: 1) hydroforming tools that included die and punches (Fig. 11b); 2) hydraulic feed which generated high pressure of the liquid medium (machine oil) [8]. Lower punch was a hole inside, which allow inject the liquid inside the tubular blank.

a)

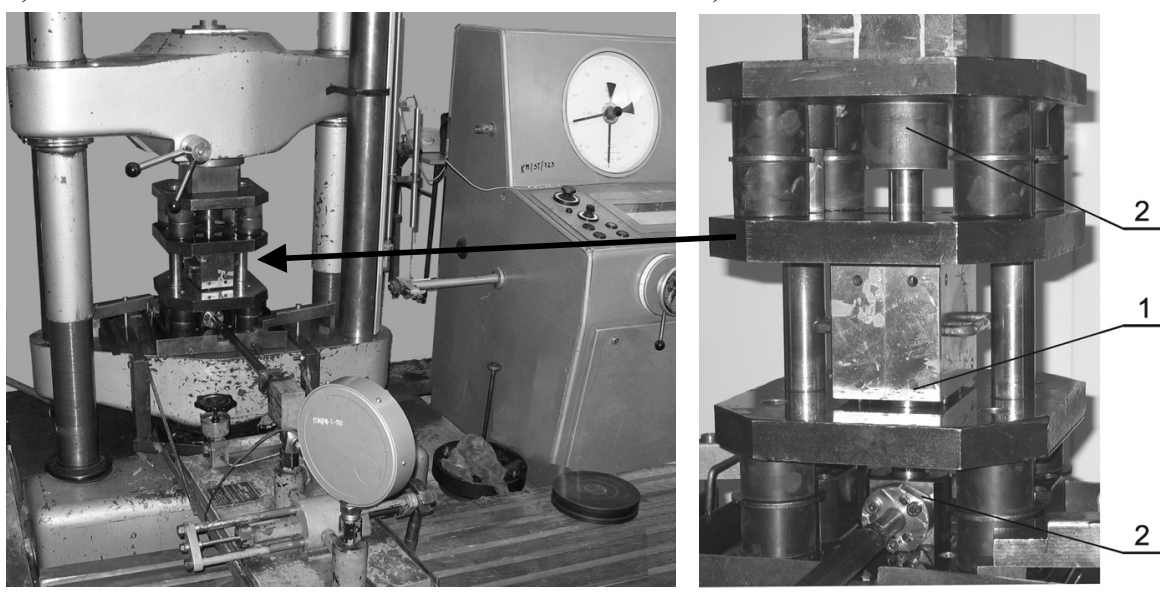

Fig. 11. The hydroforming station ZD 100 press (a) with the tools (b) for the Y-shapes forming: 1 -die; 2 - punches

On the Figure 12a axial forces variations for pressure paths from Figure 10b were illustrated. Maximum force value was for the maximum $p_{2}$ pressure that correspond to thicker tubular blank $\left(t_{0}=1.5 \mathrm{~mm}\right)$ and equal $256 \mathrm{kN}$ compared to $225 \mathrm{kN}$ and $199 \mathrm{kN}$ for $p_{5}$ and $p_{8}$ respectively. It means that the results from the numerical simulations were confirmed. 
a)

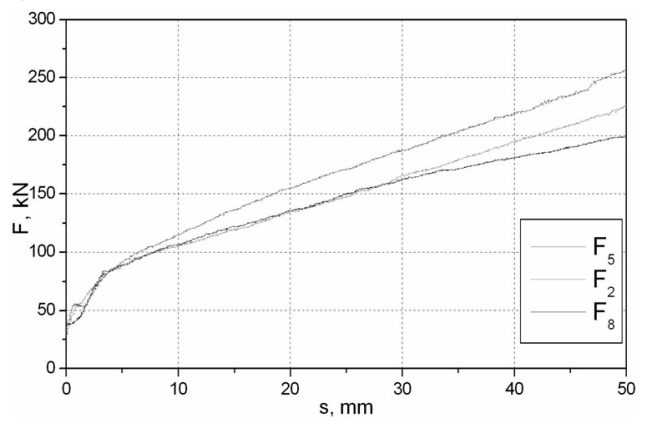

b)

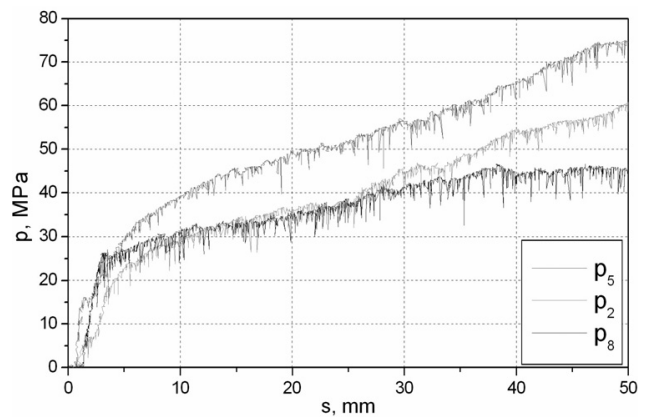

Fig. 12. Axial forces variations (a) for $p_{2}, p_{5}$, and $p_{8}$ pressure paths (b)

The thickness variations in the Y-shapes, hydroformed of $p_{2}, p_{5}$ and $p_{5}$ pressure paths, were illustrated in Figure 13. As expected maximum thinning at the top of the branch rising along with pressure paths increase, and reached $0.92 \mathrm{~mm}$ for $p_{2}, 1.25 \mathrm{~mm}$ for $p_{5}$ and 0.98 for $p_{8}$. The greatest values of the thickening at the both ends of the Y-shapes were achieved. For the same initial thickness of the tubular blanks (hydroformed with $p_{2}, p_{8}$ pressure paths) the thinning at the top edge was comparable. Differences only at the heights of the branches were visible (Fig. 14).

a)

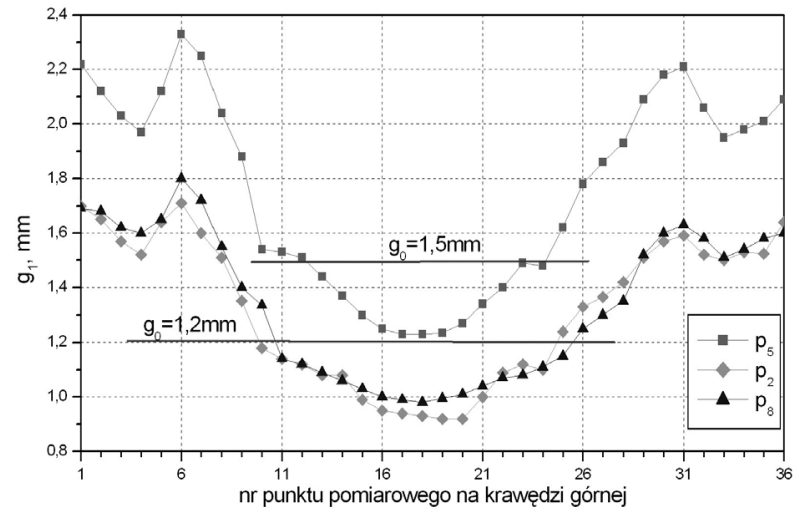

b)
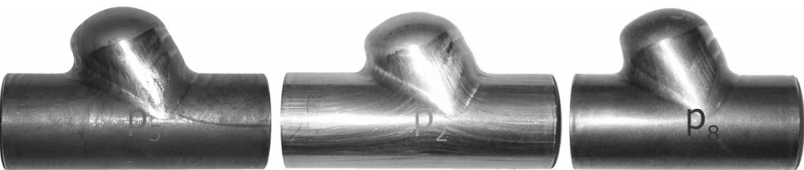

c)
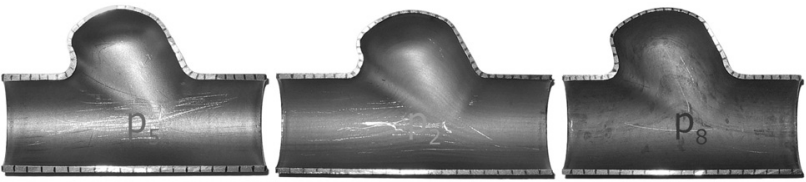

Fig. 13. Wall thickness variations (a) for $p_{2}, p_{5}$, and $p_{8}$ pressure paths along the top edge of the final parts (b) and (c) 


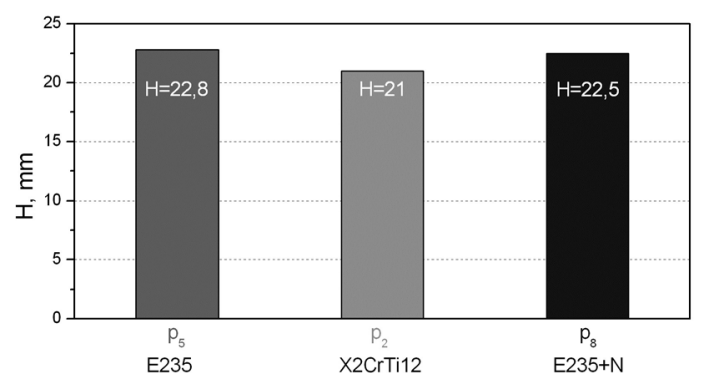

Fig. 14. Comparison of the branches height

\section{COMPARISONS FEM AND EXPERIMENTAL RESULTS}

As a confirmation of good correlations between the FEM simulation and experiment the comparison of these two results were performed. Figures 15 and 16 show pressure paths obtained for the simulations. Significant differences of the wall thickness variations were in the $r_{1}$ and $r_{2}$ areas. At the top of the branch (the crucial area of the Y-shape) these values were comparable and the maximum differences reached up to $8 \%$. Considering appearance of the final Y-shapes it was found that they have a very similar shape.

a)
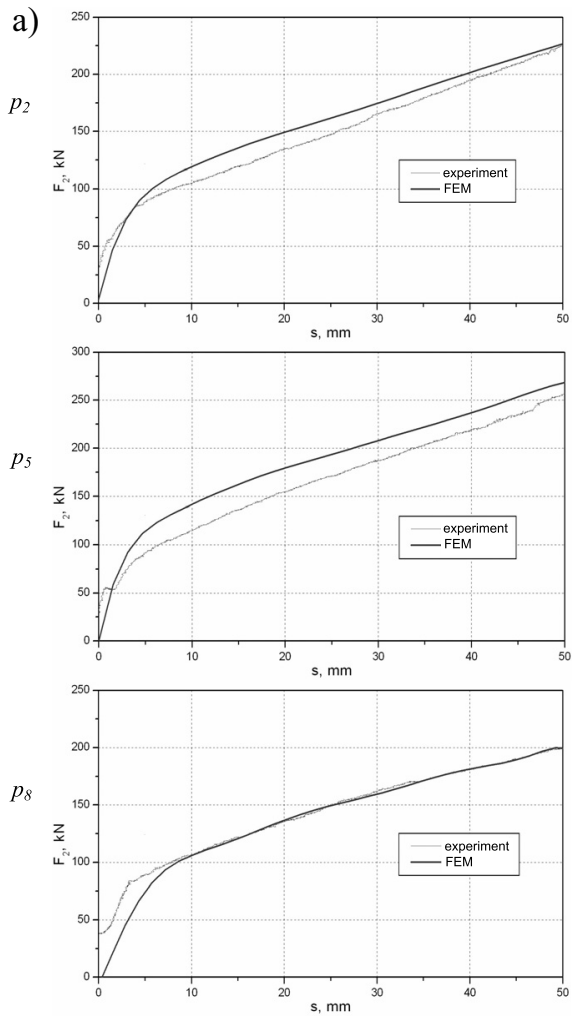

b)
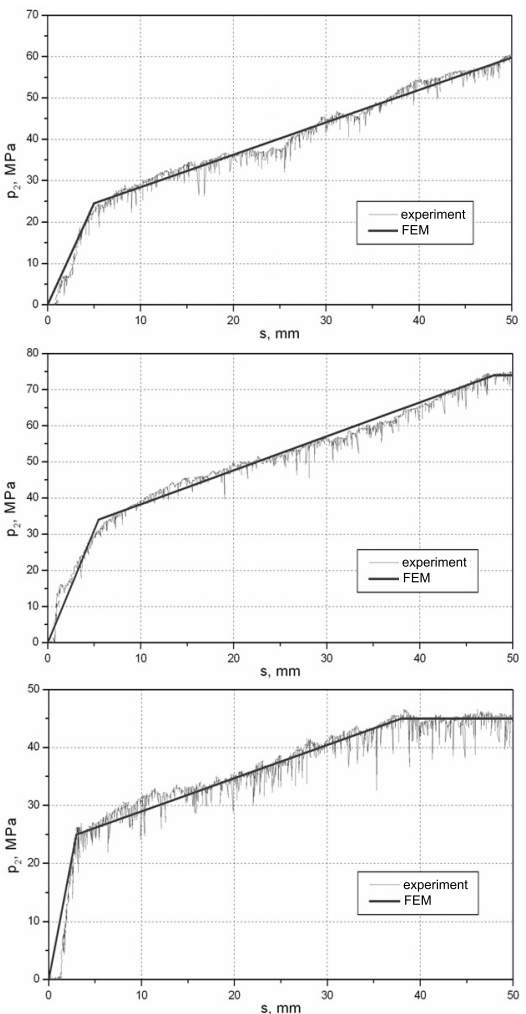

Fig. 15. Experimental and numerical comparison of results for $p_{2}, p_{5}$ and $p_{8}$ pressures: a) force; b) pressure 
a)

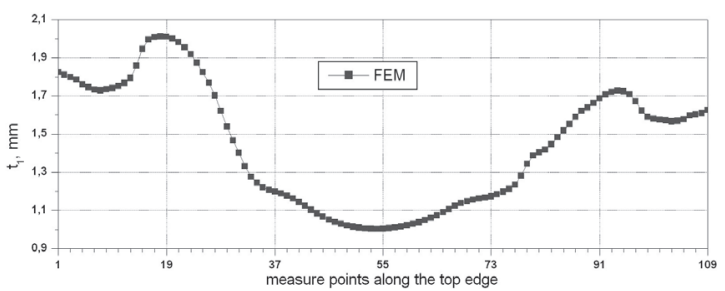

$p_{2}$
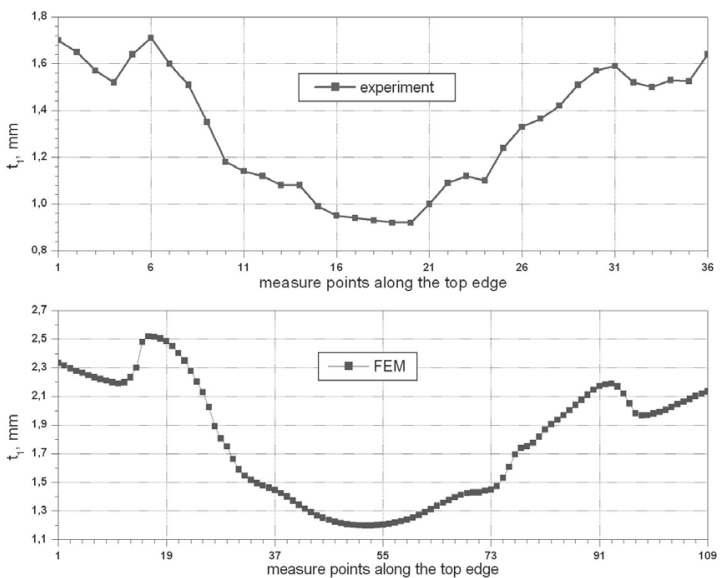

$p_{5}$
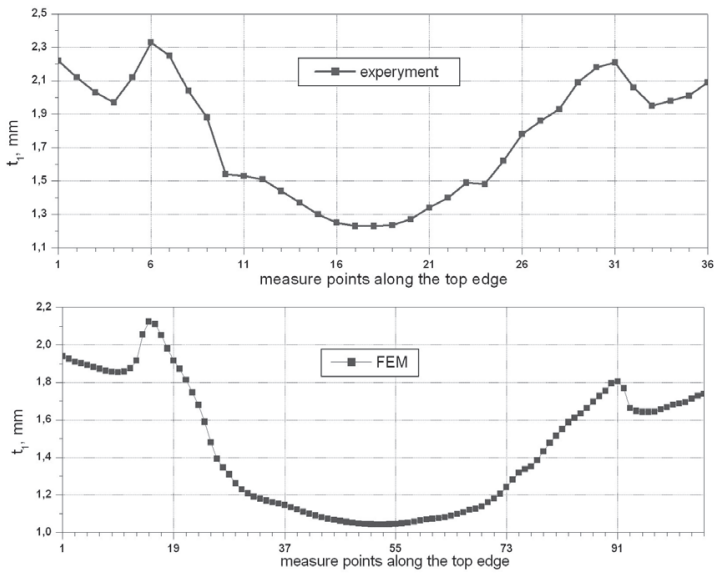

$p_{8}$

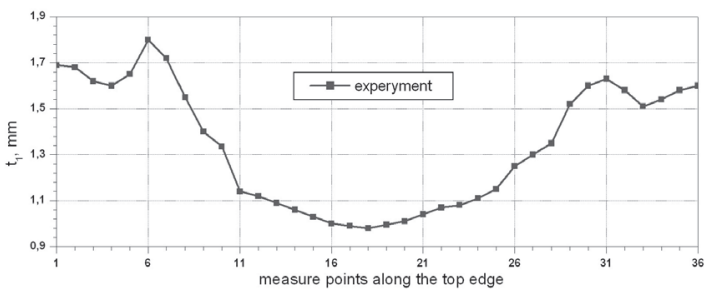

b)
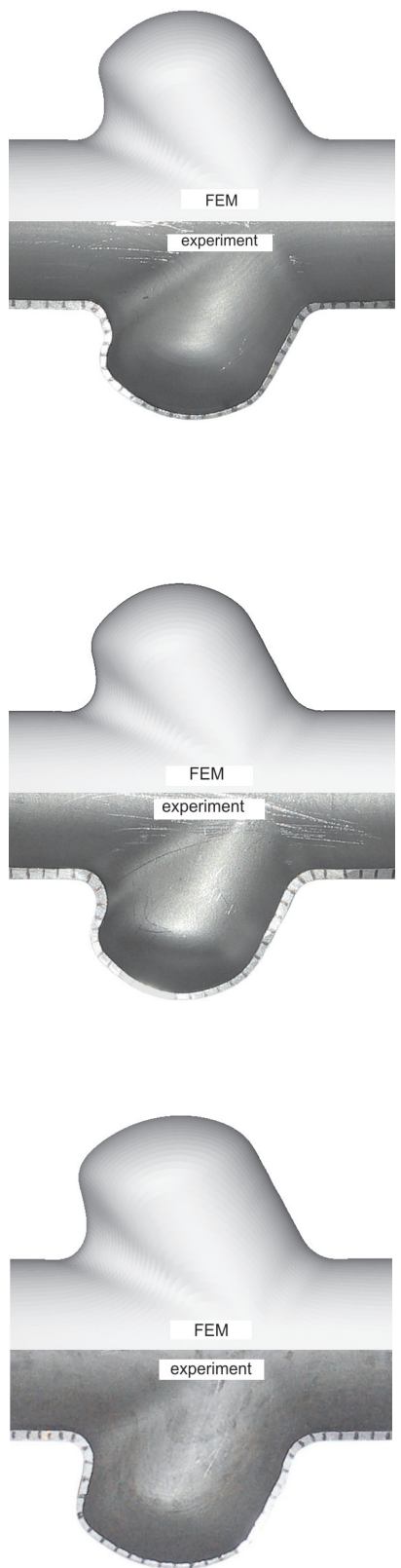

Fig. 16. Experimental and numerical comparison of results for $p_{2}, p_{5}$ and $p_{8}$ pressures: a) thickness; b) appearance 


\section{CONCLUSIONS}

Coordination of the internal pressure, axial feeding is a crucial task in achieving the maximum height of the branch without any defects and suitable thickness distributions. The results of these simulations show that increase in the pressure path affect on axial force increase. It is due to buildup of: internal pressure acting on front of the punches and tubular blank internal surface; stroke of the punches cause material thickening and hardening. The main thinning was at the top of the branch, whereas thickening was at both ends. The top branch is susceptible to excessive tension, because it has no support from the any die $[8,14]$.

In simulation as well as experiment optimal Y-shapes remains almost the same. For this reason assumed simulation parameters were confirmed.

In the FEM isotropic kind of material was utilized. It is necessary to say that use of anisotropic material should improve the results of the numerical simulations.

The influence of the mechanical parameters was investigated as well, especially ultimate tensile strength $\sigma_{u}$. The tubular blanks made with the grade steel that has higher ultimate tensile strength (X2CrTi12) are less flexible in comparison to the other $(\mathrm{E} 235+\mathrm{N})$. It means that at the final stage of hydroforming process axial feeding as well as internal pressure must have higher values to form optimal Y-shape.

\section{REFERENCES}

[1] Massoni E.: Finite element simulation of hydroforming process, Proc. Int. Conf. ESAFORM 2002, pp. $703-$ 706

[2] Lück H.-U., Hartl Ch., Abbey T.: Hydroforming, J. Mat. Proc. Techn., 115 (2001) 87-91

[3] Dochmann F., Hartl Ch.: Hydroforming-applications of coherent FE-simulations to the development of products and processes, J. Mat. Proc. Techn., 150 (2004) 18-24

[4] Stadnik R., Kazanecki J., Szymański J.: Parameters of the bellows forming process, Przegląd Mechaniczny, 7-8 (2007) 33-36

[5] Lang L.H., Wang Z.R., Kang D.C., Zhang S.J., Danckert J., Nielsen K.B.: Hydroforming highlights: sheet hydroforming and tube hydroforming, J. Mat. Proc. Techn., 151 (2004) 165-177

[6] Koc M.: Investigation of the effect of loading path and variation in material properties on robustness of tube hydroforming process, J. Mat. Proc. Techn., 133 (2003) 276-281

[7] Jirathearanat S., Hartl Ch., Altan T.: Hydroforming of Y-shape - product and process design using FEA simulation and experiments, J. Mat. Proc. Techn., 146 (2004) 124-129

[8] Stadnik R.: Tubular blanks forming process with utilize of liquid pressure, AGH, Krakow 2008, PhD thesis

[9] Jirathearanat S., Altan T.: Optimization of Loading Path for Tube Hydroforming, Mat. Conf. NUMIFORM 2004, ed. S. Ghosh, J.C. Castro, J.K. Lee, pp. 1148-1153

[10] Koc M., Altan T.: Prediction of forming limits and parameters in the tube hydroforming process, Int. J. Mach. Tools \& Manufacture, 42 (2002) 123-138

[11] Koc M., Altan T: Application of two dimensional (2D) FEA for the tube hydroforming process, Int. J. Mach. Tools \& Manufacture, 42 (2002) 1285-1295 
[12] Koc M., Allen T., Jirathearanat S., Altan T.: The use of FEA and design of experiments to establish design guidelines for simple hydroformed parts, Int. J. Mach. Tools \& Manufacture, 40 (2000) 2249-2266

[13] Hibbit, Karlsson, Sorensen: ABAQUS/Explicit User's Manual, Inc, 1998

[14] Stadnik R., Kazanecki J.: Hydroforming of a Y-shape branch, Mat. Conf. KomPlasTech2006, ed. D. Szeliga, M. Pietrzyk, J. Kusiak, pp. 327-334

Received

November 2009 